\title{
COMPARISON OF CENTRAL OBESITY WITH OVERALL OBESITY IN PREDICTING THE RISK OF TYPE 2 DIABETES MELLITUS
}

\author{
Bishal Joshi, ${ }^{1}$ Laxmi Shrestha, ${ }^{2}$ Kushal Bhattarai, ${ }^{3}$ Nilu Manandhar, ${ }^{4}$ Narayan Bahadur Mahotra ${ }^{5}$
}

\begin{abstract}
INTRODUCTION

Many studies have shown the association of waist circumference, waist hip ratio and body mass index with type 2 diabetes mellitus. Waist circumference and waist hip ratio have been used as measures of central obesity and body mass index has been used as a measure of general obesity. Objective of this study is to find out which type of obesity is better for prediction of risk of type 2 diabetes mellitus.
\end{abstract}

\section{MATERIAL AND METHODS}

Total 100 participants with confirmed diagnosis of type 2 DM with age group 35-80 years were selected for the study. Anthropometric measurements like height, weight, waist circumference (WC) and hip circumference were measured and body mass index (BMI) and waist hip ratio (WHR) were calculated. Area under receiver operating characteristic (ROC) curve was used for correlating the parameters with type 2 diabetes mellitus in both male and female patients.

\section{RESULTS}

Area under ROC curve, a measure of performance of the indices in predicting diabetes in total subjects, was found to be highest for waist hip ratio (0.840) followed by waist circumference (0.688) and BMI (0.608). Similarly, area under ROC curve was found maximum for waist hip ratio followed by waist circumference and body mass index in case of male and female patients.

\section{CONCLUSION}

The present study concludes that anthropometric indicators of central obesity (WHR and WC) are more predictive for type $2 \mathrm{DM}$ than anthropometric indicator of general obesity (BMI).

KEYWORDS Type 2 diabetes mellitus, body mass index, waist circumference, waist hip ratio

1. Department of Physiology, Universal College of Medical Sciences, Bhairahawa, Nepal

2. Department of Pharmacology, Universal College of Medical Sciences, Bhairahawa, Nepal

3. Department of Biochemistry, College of Medical Sciences, Bharatpur, Chitwan, Nepal

4. Department of Physiology, College of Medical Sciences, Bharatpur, Chitwan, Nepal

5. Department of Clinical Physiology, Maharajgunj Medicine Campus, IOM, TU, Kathmandu.

DOI: https://doi.org/10.3126/jucms.v7i1.24680

\author{
For Correspondence \\ Dr. Bishal Joshi \\ Department of Physiology \\ Universal College of Medical Sciences \\ Bhairahawa, Nepal \\ Email: drbishaljoshi76@gmail.com
}




\section{INTRODUCTION}

Diabetes is a group of metabolic diseases characterized by hyperglycaemia resulting from defects in insulin secretion, insulin action, or both. Type $1 \mathrm{DM}$ results from autoimmune beta cell destruction which leads to deficiency of insulin. Type $2 \mathrm{DM}$ is a heterogeneous group of disorders characterized by variable degrees of insulin resistance, impaired insulin secretion, and increased glucose production.

There is dramatic increase of diabetes worldwide as a consequence of changes in lifestyle, including physical inactivity and unhealthy diet. ${ }^{3}$ Several studies indicate that weight gain and obesity are associated with increased risk of diabetes and that the onset of diabetes can be prevented by weight reduction and change in life style. ${ }^{4-7}$ Body mass index, waist circumference, and waist hip ratio have been shown to be associated with type 2 diabetes. Among these anthropometric measurements, waist circumference and waist hip ratio have been used as the measures of central obesity (where visceral adipose tissue is stored), and body mass index $\left(\mathrm{kg} / \mathrm{m}^{2}\right)$ has been used as a measure of general obesity. ${ }^{8}$ From the clinical point of view, central obesity is known to generate diabetogenic substances and should, therefore, be more informative in predicting type 2 diabetes mellitus than general obesity. ${ }^{9}$ Although many aspects of clinical view supporting the central obesity is convincing, further research is needed to determine the usefulness of waist circumference or waist/hip ratio over body mass index. Therefore, we designed this study to find out the best parameter among body mass index, waist circumference and waist hip ratio to predict the risk of type 2 diabetes mellitus.

\section{MATERIAL AND METHODS}

The present study was conducted at College of Medical Sciences Teaching Hospital, Bharatpur, Chitwan. The duration of the study was nine months i.e., from January 2014 to September 2014. We included 100 patients with confirmed diagnosis of type $2 \mathrm{DM}$. Subjects with age group 35 to 80 years were selected for the study. The samples were selected from the patients visiting the OPD with confirmed diagnosis of Type 2 Diabetes Mellitus.

Diagnosis of DM was made according to the following criteria $^{10}$ (set by the WHO):

1. Symptoms of diabetes plus random blood glucose concentration $\geq 200 \mathrm{mg} / \mathrm{dL}$, or

2. Fasting blood glucose $\geq 126 \mathrm{mg} / \mathrm{dL}$, or

3. Glycated hemoglobin (HbA1C) $>6.5 \%$, or

4. Two hour blood glucose $\geq 200 \mathrm{mg} / \mathrm{dL}$ during an oral glucose tolerance test

\section{Exclusion criteria}

- Patient with serious illness

- Other specific types of diabetes mellitus

- Other causes of abdominal distension

- Pregnancy
- Study participants who are not willing to participate in the study.

\section{Procedure}

Subject with known case of diabetes mellitus type 2 were chosen as the case and their laboratory reports were obtained for confirmation. After that detailed history of study participants were taken and finally following anthropometric measurements were done.

- Weight in $\mathrm{kg}$

- Height in cm

- Waist circumference in $\mathrm{cm}$

- Hip circumference in $\mathrm{cm}$

Weight was measured using portable weighing machine. Height was measured using calibrated stadeometer. Height of the subject was measured without shoes in $\mathrm{cm}$ and then converted to meter and weight was taken in kilograms.

Waist and hip circumferences were measured as per the WHO guidelines.

- Waist and hip circumference were measured with a nonstretchable tape. Measurement was taken at standing position and bulky clothing was avoided.

- Waist circumference was measured at the approximate midpoint between the lower margins of last palpebral rib and the top of iliac crest in the mid axillary line at the end of normal expiration.

- Hip circumference measurement was taken around the widest point of buttocks.

- Both measurements were taken with a stretch resistant tape wrapping snugly around the subject keeping the tape level parallel to the floor at the point of measurement.

With the above obtained data following parameters were calculated:

1. Body mass index

$$
\mathrm{BMI}_{-}=\frac{\text { Weight }(\mathrm{kg})}{{\text { (Height in meter })^{2}}^{2}}
$$

\section{Waist hip ratio}

$$
\text { WHR }=\frac{\text { Waist circumference }}{\text { Hip circumference }}
$$

\section{Statistical analysis}

Statistical analysis was done using SPSS 20.0 version (Statistical Package for Social Science for Windows Version) and Microsoft Office Excel 2010. Area under receiver operating characteristic (ROC) curves was used as a measure of performance of indices in both male and female patients.

\section{RESULTS}

Total number of diabetic patients in the study was 100 . Out of them 53 were male and 47 were female. The mean age of the male participant was $56.40 \pm 11.086$ years and female was $56.06 \pm 11.805$ years. The mean BMI $\left(\mathrm{kg} / \mathrm{m}^{2}\right)$ of male 
participants was $24.35 \pm 3.135$ and female participants were $25.20 \pm 4.063$. Likewise, the mean waist circumference (in $\mathrm{cm}$ ) of male and female participants was $91.90 \pm 7.381$ and $87.86 \pm 8.712$ respectively. Similarly, mean waist hip ratio of male and female participants was found to be $0.994 \pm 0.031$ and $0.922 \pm 0.046$ respectively (table- 1 ).

Table 1. Mean age, BMI, WC and waist hip ratio of study participants

\begin{tabular}{llll}
\hline & $\begin{array}{l}\text { Diabetic } \\
\text { participants }\end{array}$ & Mean \pm SD & Number \\
\hline $\begin{array}{l}\text { Age of the } \\
\text { subjects } \\
\text { (In years) }\end{array}$ & Male & $56.40 \pm 11.086$ & 53 \\
& Female & $56.06 \pm 11.805$ & 47 \\
& Total & $56.24 \pm 11.373$ & 100 \\
\hline $\begin{array}{l}\text { Body mass index } \\
\text { (In kg/m }{ }^{2} \text { ) }\end{array}$ & Male & $24.35 \pm 3.135$ & 53 \\
& Female & $25.20 \pm 4.063$ & 47 \\
\hline $\begin{array}{l}\text { Waist } \\
\text { circumference }\end{array}$ & Total & $24.75 \pm 3.607$ & 100 \\
(In cms) & Fale & $91.90 \pm 7.381$ & 53 \\
& Total & $87.86 \pm 8.712$ & 47 \\
& Male & $90.00 \pm 8.246$ & 100 \\
\hline Waist hip ratio & Female & $0.994 \pm 0.031$ & 53 \\
& Total & $0.922 \pm 0.046$ & 47 \\
\hline
\end{tabular}

\section{Comparison of BMI, WC, and WHR in male subjects}

In male participants, area under the curves for $\mathrm{WC}, \mathrm{WHR}$ and BMI are $0.705,0.918$, and 0.640 respectively. So, the area under ROC curve, a measure of the performance of the indices in predicting diabetes in female subjects, was found to be highest for waist hip ratio followed by waist circumference and BMI (Fig-1).

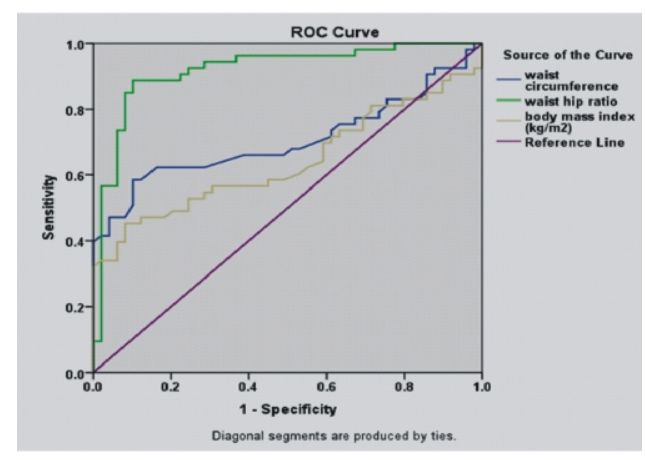

Area Under the curve for $\mathrm{WC}=0.705$; Area Under the curve for $\mathrm{WHR}=0.918$; Area Under the curve for $\mathrm{BMI}=0.640$

Figure 1. Comparison of the ROC curves of WC, WHR and $\mathrm{BMI}$ in male subjects

\section{Comparison of BMI, WC, and WHR in female subjects}

In case of female participants, area under the curves for WC, WHR and BMI are $0.675,0.902$ and 0.594 respectively. So, the area under ROC curve, a measure of the performance of the indices in predicting diabetes in female subjects, was found to be highest for waist hip ratio followed by waist circumference and BMI (Fig-2).

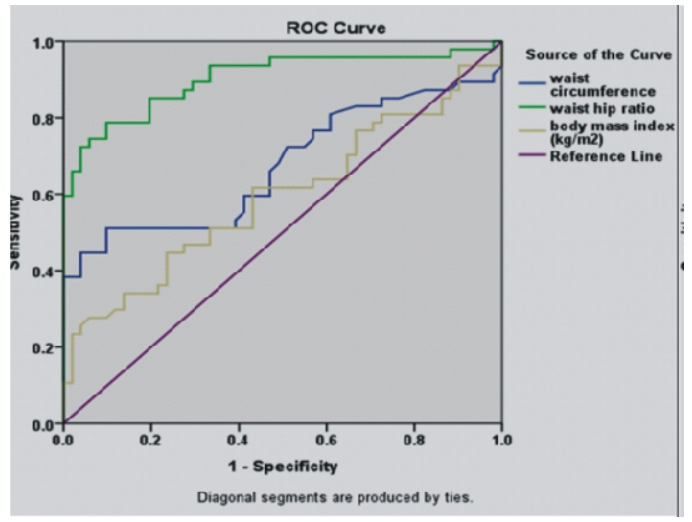

Area Under the curve for $\mathrm{WC}=0.675$; Area Under the curve for $\mathrm{WHR}=0.902 ;$ Area Under the curve for $\mathrm{BMI}=0.594$

Figure 2. Comparison of the ROC curves of WC, WHR and $\mathrm{BMI}$ in female subjects

\section{Comparison of BMI, WC, and WHR in total subjects}

In case of total participants, area under the curves for WC, WHR and BMI are $0.688,0.840$ and 0.608 respectively. So, the area under ROC curve, a measure of the performance of the indices in predicting diabetes in total participants, was found to be highest for waist hip ratio followed by waist circumference and BMI (Fig-3).

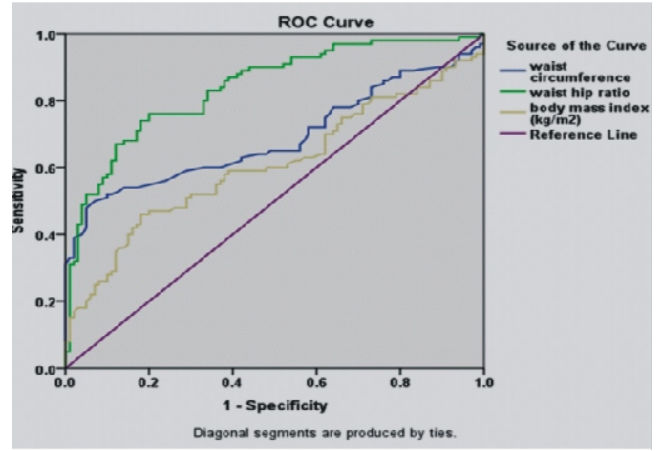

Area Under the curve for $\mathrm{WC}=0.688$; Area Under the curve for WHR $=0.840 ;$ Area Under the curve for $\mathrm{BMI}=0.608$

Figure 3. Comparison of the ROC curves of WC, WHR and $\mathrm{BMI}$ in total subjects 


\section{DISCUSSION}

Increase in obesity is one of the serious health problems in the present world as it is intimately related with the rate of development of diabetes mellitus and cardiovascular diseases resulting in a dramatic increase in morbidity and mortality. In recent years, BMI, WHR and waist circumference are changed significantly with the elevation of living standard and sedentary lifestyle, and the mean BMI in adults is increasing in both developed and developing countries. ${ }^{12}$

It is already an established fact that, increase in body mass index, waist circumference and waist hip ratio increases the risk for type 2 diabetes mellitus. In this study, we compared waist circumference, waist hip ratio and body mass index to find out the better parameter for prediction of type 2 diabetes mellitus. In this cross sectional study we found that both generalized obesity (measured by BMI), and central obesity (measured by waist circumference and waist hip ratio) predict type 2 diabetes mellitus. The comparison of ROC curve for BMI, WC and WHR in case of male, female and total patients showed that AUC is highest for waist hip ratio followed by waist circumference and BMI. This shows that among male and female patients waist hip ratio and waist circumferences are the better predictors of type 2 diabetes mellitus than body mass index. This also concludes that central obesity is better predictor of type 2 diabetes mellitus than generalized obesity.

Many cohort study, conducted previously to compare different anthropometric measurements with regard to diabetes risk prediction suggest that anthropometric measurements that describe central obesity (waist circumference and waist hip ratio) may be superior to measurements of general adiposity (BMI). ${ }^{13-15}$ Similarly, many other studies compared waist circumference and body mass index and found waist circumference to be better correlated with the risk of type 2 diabetes mellitus. ${ }^{16-18}$ In a similar study by Wang et al, ${ }^{19}$ comparing the WHR and BMI the results showed that AUC for WHR was greater than BMI indicating WHR more convincing for prediction of type $2 \mathrm{DM}$.

The present study suggests that waist hip ratio and waist circumference are the better indicators for predicting diabetes than body mass index. This is also consistent with findings from many other studies. Many prospective studies have also shown that abdominal obesity is a major risk factor for the development of type 2 diabetes. ${ }^{20}$

There has been much debate about the best parameter among BMI, WC and waist hip ratio to predict the risk of metabolic diseases like diabetes mellitus. Although many studies have used body mass index as an indicator of obesity, our results from ROC curve showed that WHR and WC are the better indictors of risk of diabetes than BMI. The possible pathophysiological explanation is that large amounts of visceral fat cause insulin resistance because lipolysis of visceral adipose tissues releases free fatty acids ${ }^{21}$ and excess intra-abdominal adiposity may have the potential to influence metabolism through alterations in the secretion of adipokines. $^{22}$

\section{CONCLUSION}

This study concludes that waist hip ratio and waist circumference are the better predictors of type 2 DM compared to body mass index in both male and female patients. WHR and WC have higher area under ROC curve in case of both male and female diabetic patients. It indicates that anthropometric indicators of central obesity (WHR and WC) are more predictive for type $2 \mathrm{DM}$ than anthropometric indicator of overall obesity (BMI). But all the three parameters are useful in prediction of risk of type 2 diabetes and further large population based studies are required.

\section{REFERENCES}

1. American Diabetes Association. Diagnosis and classification of diabetes mellitus. Diabetes Care. 2014 Jan;37(Supplement1) : S8 -90.

2. Powers AC. Harrison's principles of internal medicine. In: Fauci AS, Braunwald E, Kasper DL, Hauser SL, Longo DL, Jameson JL, editor. 16th ed. New York: McGraw Hill Companies Inc; 2008. p. 2139-54.

3. Zimmet P, Alberti KG, Shaw J. Global and societal implications of the diabetes epidemic. Nature. 2001 Dec;414(6865):782-7.

4. Pan XR, Li GW, Hu YH, Wang JX, Yang WY, An ZX, Hu ZX, Xiao JZ, Cao HB, Liu PA, Jiang XG. Effects of diet and exercise in preventing NIDDM in people with impaired glucose tolerance: the Da Qing IGT and Diabetes Study. Diabetes Care. 1997 Apr;20(4):537-44.

5. Kosaka K, Noda M, Kuzuya T. Prevention of type 2 diabetes by lifestyle intervention: a Japanese trial in IGT males. Diabetes research and clinical practice. $2005 \mathrm{Feb} ; 67: 152-62$.

6. Ramachandran A, Snehalatha C, Mary S, Mukesh B, Bhaskar $\mathrm{AD}$, Vijay V. The Indian Diabetes Prevention Programme shows that lifestyle modification and metformin prevent type 2 diabetes in Asian Indian subjects with impaired glucose tolerance (IDPP-1). Diabetologia. 2006 Feb;49(2):289-97.

7. Hussain AM, Hydrie MZ, Claussen B, Asghar S. Type 2 diabetes and obesity: a review. Journal of Diabetology. 2010 Jun;2(1):17.

8. Molarius A, Seidell JC. Selection of anthropometric indicators for classification of abdominal fatness a critical review. Int J ObesRelatMetab Disord.1998;22(8):719-27.

9. Jensen MD. Is visceral fat involved in the pathogenesis of the metabolic syndrome? Human model. Obesity. 2006 Feb;14:204. 
10. Nishida C, Ko GT, Kumanyika S. Body fat distribution and noncommunicable diseases in populations: overview of the 2008 WHO Expert Consultation on Waist Circumference and WaistHip Ratio. European Journal of Clinical Nutrition. 2010 Jan;64(1):2-5.

11. Clinical guidelines on the identification, evaluation, and treatment of overweight and obesity in adults: executive summary. Expert Panel on the Identification, Evaluation, and Treatment of Overweight in Adults. Am J ClinNutr. 1998;68 (4):899-917.

12. Zheng RD, Chen ZR, Chen JN, Lu YH, Chen J. Role of body mass index, waist-to-height and waist-to-hip ratio in prediction of nonalcoholic fatty liver disease. Gastroenterology research and practice. 2012;2012:1-6.

13. Folsom AR, Kushi LH, Anderson KE, Mink PJ, Olson JE, Hong CP, Sellers TA, Lazovich D, Prineas RJ. Associations of general and abdominal obesity with multiple health outcomes in older women: the Iowa Women's Health Study. Archives of Internal Medicine. 2000 Jul;160(14):2117-28.

14. Stevens J, Couper D, Pankow J, Folsom AR, Duncan BB, Nieto FJ, Jones D, Tyroler HA. Sensitivity and specificity of anthropometrics for the prediction of diabetes in a biracial cohort. Obesity research. 2001 Nov;9(11):696-705.

15. Snijder MB, Dekker JM, Visser M, Bouter LM, Stehouwer CD, Kostense PJ, Yudkin JS, Heine RJ, Nijpels G, Seidell JC. Associations of hip and thigh circumferences independent of waist circumference with the incidence of type 2 diabetes: the Hoorn Study. The American Journal of Clinical Nutrition. 2003 May;77(5):1192-7.

16. Ford ES, Mokdad AH, Giles WH. Trends in waist circumference among US adults. Obesity research. 2003 Oct;11(10):1223-31.
17. Wei M, Gaskill SP, Haffner SM, Stern MP. Waist circumference as the best predictor of noninsulin dependent diabetes mellitus (NIDDM) compared to body mass index, waist/hip ratio and other anthropometric measurements in Mexican Americansa 7-year prospective study. Obesity research. 1997 Jan;5(1):1623.

18. Janssen I, Katzmarzyk PT, Ross R. Waist circumference and not body mass index explains obesity-related health risk. The American Journal of Clinical Nutrition. 2004 Mar;79(3):37984.

19. Wang Z, Rowley K, Wang Z, Piers L, O'dea K. Anthropometric indices and their relationship with diabetes, hypertension and dyslipidemia in Australian Aboriginal people and Torres Strait Islanders. European Journal of Cardiovascular Prevention \& Rehabilitation. 2007 Apr;14(2):172-8.

20. Wang Z, Hoy WE. Body size measurements as predictors of type 2 diabetes in Aboriginal people. International Journal of obesity. 2004 Dec;28(12):1580-4.

21. Fontana L, Eagon JC, Trujillo ME, Scherer PE, Klein S. Visceral fat adipokine secretion is associated with systemic inflammation in obese humans. Diabetes. 2007 Apr;56(4):10103.

22. Despres JP, Moorjani S, Lupien PJ, Tremblay A, Nadeau A, Bouchard C. Regional distribution of body fat, plasma lipoproteins, and cardiovascular disease. Arteriosclerosis. 1990 ;10 (4):497-511. 